Elsevier required licence: (C) <2019>. This manuscript version is made available under the CC-BY-NCND 4.0 license http://creativecommons.org/licenses/by-nc-nd/4.0/

The definitive publisher version is available online at

[https://www.sciencedirect.com/science/article/pii/S0301421518308565?via\%3Dihub] 
Energy Policy, 2019, pp. 125 - 135

\title{
Can energy-price regulations smooth price fluctuations? Evidence from China's coal sector
}

\author{
Yanfang Zhang ${ }^{1,2}$, Rui $\mathrm{Nie}^{1}$, Xunpeng Shi ${ }^{2,3,4 *}$, Xiangyan Qian ${ }^{1}$, Ke Wang $^{5,6,7}$ \\ 1 School of Management, China University of Mining and Technology, Xuzhou 221116, China \\ 2 University of Technology Sydney, Australia-China Relations Institute, Ultimo NSW 2007, \\ Australia \\ ${ }^{3}$ Center of Hubei Cooperative Innovation for Emissions Trading System \& School of Low Carbon \\ Economics, Hubei University of Economics, Wuhan, China \\ ${ }^{4}$ Energy Studies Institute, National University of Singapore, Singapore 119620 \\ ${ }^{5}$ Center for Energy and Environmental Policy Research \& School of Management and Economics, \\ Beijing Institute of Technology, Beijing, China \\ ${ }^{6}$ Sustainable Development Research Institute for Economy and Society of Beijing, Beijing, China \\ ${ }^{7}$ Beijing Key Lab of Energy Economics and Environmental Management, Beijing, China
}

\begin{abstract}
Due to the dominance of coal in China's energy mix, coal prices have always been a challenge part of pricing reform. The recent frequent government interventions raise the key research questions: what is the actual impact of price policies on coal price fluctuations, and how can forward-looking pricing policies be made. By proposing a novel classification of coal pricing policies and introducing an expectation and forward-looking coefficient, the paper examines the relationship between coal price fluctuations and pricing policies using the generalized method of moments (GMM) method. It shows that the lagging coal price and coal demand play a positive role in regulating coal prices, while coal supply and marketization have significantly negative effects on coal price fluctuations. The heterogeneous impacts of price policies are due to differences in market players' expectations, policy instruments and the method of policy release. In addition, China's coal pricing policy portfolio from 2013 to 2016 exerted synergy effects on the restraint of coal price fluctuations. As the forward-looking coefficient was considerably low, the government's intervention behaviors were obviously biased towards ex post facto responses. The paper suggests short run and long run policy to advance marketization of coal prices amid the energy transition.
\end{abstract}

Key words: coal; price fluctuations; pricing policy; forward-looking coefficient; GMM model; China

*Corresponding author (Xunpeng Shi). E-mail: xunpeng.shi@gmail.com 


\section{Introduction}

Over the past few years and installment of the current leadership, energy pricing reform has been highlighted in China's national reform agenda. According to the Third Plenary Session of the 18th CPC Central Committee in November 2013, the Chinese government will not intervene in any prices (except network prices) that can be determined by the market (18th Central Committee of CPC, 2013). The "Energy Revolution" announced by President Xi Jinping in June 2014 further demanded restoration of the commodity characteristic of energy products and the establishment of market- based energy pricing mechanisms. More action plans have subsequently been released by the State Council.

Though China has accepted the status of a market economy, pricing policies are still used and their frequency is particularly high in China's coal industry. Give the significant of coal in China's energy mix, marketization of coal prices has a wide impact on economy and thus reform of coal prices is still in the process along with the changes of coal market. In the "pre-liberalization" stage until the early 2000 s, the government set a guided-price for coal based on which coal producers and large consumers to negotiate their contracts during an annual coal ordering conference ("meitan dinghuohui"). Then in 2005, China liberalized its coal price and let the producers and consumers to freely determine their coal prices (Shi, 2009). However, due to the importance of the coal industry in the Chinese national economy, the government often resorts to policy interventions to keep balance among the economic growth, energy supply and industrial development (Shi, 2013; Shi et al., 2018; Zhang et al., 2018). 
According to the CEIC database, China's thermal coal price maintained a upward trend between 2005-2012 due to the shortage of coal supply. To curb the coal price incrase, the Chinese government issued a series of temporary pricing policieso, such as coal price ceiling (Zhang et al, 2018).

However, there has been more frequent intervention in coal prices after 2012. Unexpectedly, China's coal prices enterred into a declining path aftater 2012, although with ups and downs, due to shrinkage of demand and supply overcapacity. Nevertheless, due to some significant changes in the release ministries, many policy instruments have been tweaked. ${ }^{1}$ For example, in order to curb the severe price fluctuations, the State Council canceled the dual-track system of coal prices including the contract price and the market price in 2012. Then in 2015, "the improving mechanism of coal-electricity price linkage" was published by the NDRC to ease the price conflict between coal and power companies. Meanwhile the NDRC also jointly issued a "pre-warning mechanism for abnormal coal price fluctuations" with other departments, in the expectation of a suppression in coal price fluctuations. More drastically, in early 2016, the central government put a cap on the working day at coal mines (State Council, 2016), and set three-grade responsive measures ${ }^{2}$ to curb prices (Shi et al., 2018).

However, past experience suggests that despite being initiated with specific goals, such price regulations often lead to outcomes that diverge from the original intentions due to

\footnotetext{
${ }^{1}$ The main ministries releasing coal pricing policies in China include the State Council, National Development and Reform Commission (NDRC), National Energy Administration (NEA), State Administration of Coal Mine Safety (CMS), China National Coal Association (CNCA), China Electricity Council (CEC) and China Iron and Steel Industry Association (CISA).

${ }^{2}$ The three-grade responsive measures issued by the NDRC are about three different sets of policies corresponding to three different grades, or levels of prices, representing by the FOB Bohai rim coal benchmark price (incl. VAT). The higher the benchmark prices, the more relaxation of capacity control policy and thus the higher the supply.
} 
the lack of a forward-looking design of policy subjects, policy instruments and enforcement mechanisms (Andrews-Speed et al., 2005). A recent study also demonstrates that such energy price interventions will cause negative impact on economic growth (Shi and Sun 2017). While China's control of emissions and energy transition have necessitated cuts in fossil energy consumption, especially coal consumption, due to the need of smooth transition to sustain the e economic growth, coal will still accounts for xx percent of China's energy mix in 2040 (BP, 2018). Given this, how to formulate forward-looking policies to effectively improve market-based pricing mechanisms has become an urgent issue in China's energy pricing reform.

Studying the Chinese coal pricing regimes is not only important for the development of coal industry in China and many other countries. The study can inform further policy development on coal pricing, which is lagged behind the national goal of marketization. Despite reduced coal consumption in recent years, China's share of global coal consumption expanded from about 30 percent in the early 2000s to 50.7 percent in 2017 (BP, 2018), and now accounts for around 15-25 percent of global imports (ITC, 2017). China's coal price, which is sensitive to different pricing regimes, affects global coal trade and its prices. For example, Australian coal companies recorded increases in profits in 2016 due to China's policy to cut capacity (Bloxham, 2018).

Despite of the significance of price issues in China's coal industry, the findings from previous studies on the causes of price fluctuations generally lack in-depth analysis of policy factors but focus more on market fundamentals. Moreover, the literature on the different effects of policy instruments is limited due to data limit, and a great deal of 
work remains to be done on forward-looking estimations of energy pricing policy with consideration of expectations.

To fill the literature gap, this paper focuses on coal pricing policies, of which the policy goal is to regulate prices, investigates their impact on coal price fluctuations in China and evaluates the forward-looking level of the issued policies. Specifically, an attempt is made to answer these questions: "What are the actual effects of pricing policies on coal price in China?", "are the effects different among different policy instruments?" and "how much forward-looking level is the coal pricing policy?" The focus is on coal price marketization and the government's direct and indirect interventions. In an attempt to better understand the effectiveness of pricing policies on coal price fluctuations, this paper opens with an examination of the pricing policies in China's coal sector and establishes a forward-looking coefficient to analyze the heterogeneous effects of different policy instruments on coal prices.

The contributions of this paper are four-fold. First, taking the pricing policies into account, we conduct an innovative investigation of the causes of coal price fluctuations, revealing the rules for smoothing out price fluctuations for the optimization of China's energy mix. Second, the simulation of the proxy policy variables and GMM model are employed to analyze the effectiveness of pricing policy quantitatively, broadening the empirical literature of policy evaluation. Third, such a study about the forward-looking level of pricing policies is valuable in implementing the marketization of energy prices in the future. Fourth, as China is the biggest energy consumer worldwide, the significant exploration on price interventions in China's coal market provides valuable references 
for energy pricing policy in other countries.

The paper is organized as follows: section 2 generalizes the coal pricing policies in China and related literature. Section 3 designs the measurable proxy variables of the issued coal price policies and develops the empirical models to describe the relationship among coal price, pricing policies, coal supply and demand based on the transmission mechanism of coal price fluctuations. It then introduces market players' expectations to establish a forward-looking coefficient. In section 4, we discuss the heterogeneous impact of pricing policies on China's coal prices and the forward-looking level of pricing policies under different stages. Finally, section 5 concludes the paper and provides some policy implications for China's government to promote coal price marketization smoothly.

\section{Background of pricing policies in China's coal industry}

\subsection{A brief account of prices and pricing mechanisms}

Coal industry has always been an important support for China's economic development.

To help stabilize coal price fluctuations, the government has typically held a coal ordering meeting ("meitan dinghuohui”) for the signing of coal supply contracts each year. Due to the weakened pressure on supply security, thanks partly to the declined role of coal in national energy mix, the reform of coal pricing regimes was gradually started since 2005 (see Figure 1). Beginning in 2006 however, the NDRC changed the meeting into a coal joint one (“Chan-Yun-Xu Xianjiehui") among coal manufacturers, consumers and transporters, and initiated some measures aimed at market-oriented reforms for coal orders (Shi, 2009). This was the beginning of the marketization of coal 
industry in China. In 2007, the NDRC canceled this joint meeting and stated that the marketization mechanism of coal prices would become one of the major changes in China's energy strategy in the coming decades. Furtherly, during the period of 20082011, the NDRC issued a series of temporary price policies to curb the frequent fluctuations in coal prices, especially for thermal coal.

Since 2012, China's coal prices have experienced dramatic ups and downs due to shrinkage of demand and supply overcapacity. As shown in Figure 1, the price of thermal coal spot price (Qinhuangdao port, 5500kcal $\mathrm{kg}$ ) fell from 900 yuan/ton in June 2008 to 360 yuan/ton in December 2015, and then reached a rapid rebound with a rise to 680 yuan/ton at the end of $2016 .^{3}$ In 2012-2016, the State Council, NDRC and other energy administrations implemented a marketization price reform for thermal coal and other pricing policies to curb the severe fluctuations in coal prices. Overall, the government's interventions have been relatively concentrated in the periods of sharp price fluctuations.

\section{[Insert Figure 1]}

\subsection{Analysis of coal pricing policies in different stages}

With the above background in mind, this paper examines the characteristics of national coal pricing policies from the release ministries and policy instruments. Note that the government established the National Energy Administration in 2008 and that among

\footnotetext{
${ }^{3}$ China Coal Resource Database, http://www.sxcoal.com/
} 
several other things, the changes in government organizations may generate an endogenous influence on the relationship between coal price fluctuations and pricing policies. The pricing policies discussed in this paper are those that were formulated by the state administrations between 2008 and 2016. Meanwhile, according to the differences in policy instruments, we divided the sample pricing policies into a direct intervention stage (2008-2012) and an indirect intervention stage (2013-2016).

\subsubsection{Direct intervention stage (2008-2012)}

In 2008-2012, the coal supply situation in China was generally tight and the interventions were conducted mainly in a series of direct price restriction policies (see Table 1) such as the coal price ceiling. After the implementation of these policies, the rising trend in coal prices seems was curbed. The characteristics of the coal pricing policies at this stage were as follows:

Single-ministry policy: Table 1 shows that the direct intervention policies were issued by the NDRC, i.e. a single ministry. Such policies may cost more time in terms of information transmission among government departments, and concomitantly affect the policies' influence on coal price fluctuations.

\section{[Insert Table 1]}

Single policy instrument: The direct intervention policies at this stage were basically released after a significant rise in coal prices. The policy tools adopted were mainly the setting of a coal price ceiling, indicating that the coal pricing policies in this stage were 
homogeneous. This provides an opportunity to design a measurable proxy variable of pricing policies to examine the impact on coal price fluctuations.

\subsubsection{Indirect intervention stage (2013-2016)}

The government began to use indirect policy instruments to regulate the price decline between 2013 and 2016. A typical policy was the "Notice on deepening the marketoriented reform of thermal coal price"(State Council, 2012) issued at the end of 2012, by which the government encourage coal enterprises to sign medium- and long-term contracts with market-oriented coal prices while price restriction policies were employed again when coal prices rose dramatically in 2016 (Shi et al, 2018). In general, China's coal price policies were characterized by the indirect monitoring of the medium- and long-term coal contracts during this period, as shown in Table 2, and have two outstanding features:

Joint-ministry policy: From the perspective of resource integration, the joint-ministry policies can, to a certain extent, reduce policy distortions by improving the accuracy of market player's expectation of policy effectiveness, i.e. policy expectations.

Diversified policy instruments: The government adopted mainly medium- and longterm coal contracts despite direct intervention still occurred during this stage. This indicates that a synergy effect or crowding-out effect maybe active in the policy portfolio, which in turn could distort the effectiveness of pricing policies.

[Insert Table 2] 


\subsection{Relevance to the literature}

Examining the changes in China's coal pricing policies provides good examples for studying the debates over the effectiveness of pricing policies in general, and in the specific case of China. To date not only have there been few studies on the relationship between energy price fluctuation and government regulation, but their findings have been inconclusive. Most of the studies on the causes of energy price fluctuations have focused on the changes in market supply and demand. Few studies have been carried out on policy factors, and the dominant factors affecting energy prices have not yet been agreed upon (Ellerman, 1995; Ma et al., 2009; Zhang and Cheng, 2011; Ding et al., 2017). Kanamura (2009) empirically concluded that the energy supply curve determines the characteristics of energy price fluctuations. Wang et al., (2013) proved that the impact of changes in coal demand on China's coal prices is larger than that of changes in coal supply. Separately, Ma and Oxley (2010) suggested that there are significant differences in the co-integration relationship between China's regional energy prices and the influencing factors. Unlike the above studies, Adelman (1974) explored the influence of policy factors on energy prices. His work has gradually attracted the attention of energy economists (Bernanke et al., 1997; Leduc and Sill, 2004; Edelstein and Kilian, 2009). Besides, other scholars empirically concluded that price distortions caused by pricing mechanism, taxation policy and others energy policies, would affect China's economic development and social welfare; this definitively proves the role of energy policies in regulating price fluctuations (Wang et al., 2009; Ji et al., 2014; Wang and Tian, 2015; Sun et al., 2016; Ju et al., 2017; Shi and 
Sun, 2017).

This paper is related to two broad literatures. One concerns the impact of pricing policies on prices. The other relates to the lag effect of pricing policies and the role of expectation. First, empirical examination of the impacts of pricing policies on coal price fluctuations in China is widely regarded as a challenging task since the released policies are mainly categorized into text paradigms and policy instruments (Zhao et al., 2010). Oikonomou et al. (2012) qualitatively compared the effectiveness of single energy policies versus a policy portfolio and concluded that the latter is not necessarily better than the former. Further, Yoon and Sim (2015) analyzed South Korea's renewable energy policies qualitatively and found that different policy portfolios have different effects on the price of renewable energy generation. Though the above literature lacks the effect analysis of governmental interventions on China's coal prices, it does provide a meaningful elucidation of the differential impacts of a single price policy versus a policy portfolio on coal price fluctuations.

Second, there is a consensus that the release and implementation process of any policy, including pricing policy, takes time and thus expectation has an important role. Li (2014) proposed that the effectiveness of the policy depends on the expectation factors and the policy is effective only when the expected change is in line with the policy goal. Sheffrin (1996) defined "expectation" as the predictions about uncertain economic variables made by the economic subjects. Other scholars proposed that the expectation essentially reflects whether a certain policy is forward-looking owing to the economic subjects' predictions following the implementation of pricing policies (Zheng et al., 
2012; Best and Kapinos, 2016; Zhang and Dang, 2018). And forward-looking policy studies of energy price regulation still need more literature support (Lüthi and Wüstenhagen, 2012).

In China, after the government issues coal pricing policies, the market players then make the prediction whether the pricing policy will meet its objectives in the future or not, i.e. policy expectation, which eventually reflects the forward-looking level of the policy. Disagreement over the simultaneous impacts of price fluctuations and market expectation, has existed since the 1990s (Kilian, 2009; Liu et al., 2017; Zhang et al., 2017). Given this, this paper introduced expectations of market supply and demand balance and effectiveness of policy, i.e. market expectation and policy expectation, to examine the relationship between coal price fluctuations and pricing policies. It then chose policy expectation to quantitatively evaluate the forward-looking level of coal pricing policies in China.

\section{Methodology and data}

\subsection{Proxy variables of coal pricing policy}

In this paper, we analyzed the characteristics of coal pricing policies in different stages and found that price restrictions and medium- and long-term coal contracts are the two typical instruments used to regulate coal prices in China in 2008-2016. In order to eliminate the endogenous relationship between coal prices and policy factors, we designed the proxy variables from the above two policy instruments.

(1) The proxy variable of the price restriction policies

Considering that the policy objective of the direct price restriction policies (RCP) was 
to regulate coal price so that it would remain within the targeted levels, we chose the Retail Price Index (RPI-X) model, which means that the price deviation of a product cannot exceed the difference between the RPI (one of the benchmark economic variables) and the ratio X set by the regulator (Weyman-Jones, 1990; Littlechild, 2014; Simshauser, 2017). Further, we assumed that without price restriction policies, coal price fluctuations in China generally meet the characteristics of a market economy, that is, the domestic coal price will change in accordance with the fluctuation of international coal prices under the condition that coal can be freely traded. ${ }^{4}$ This indicates that the difference between the two should tend to be stable along with the geographical differences. Conversely, with the price restriction policies, domestic coal prices deviate from international coal prices and the difference between the two remains unstable.

To reflect the variation in the discrete distribution of China's coal prices and international coal prices, following the practice of Shi and Sun (2017), this paper defined the standard deviation of the difference between the two as the proxy variable of price restriction policies based on the RPI-X model (Eq. 1). Meanwhile, many countries commonly refer to three international benchmark coal prices during the process of pricing coal, including South Africa (Richards Bay), ARA port (the Netherland) and Australia (Newcastle port) (Haris and Tao, 2016). ${ }^{5}$ Papiez and Śmiech (2013) found that coal price in Australia (Newcastle port) is the most important factor

\footnotetext{
4 "As the main the largest coal consumer and a major coal importer in the world, China's coal market is integrated with the global coal market."

${ }^{5}$ Since the Asia-Pacific region is the major destination of the global seaborne coal trade, all three benchmark coal prices are relevant to the Asia-pacific market.
} 
in shaping other prices on the Pacific markets while coal prices in ARA port and South Africa (Richards Bay) are the Granger cause of prices in the Pacific region. Consequently, we adopted the above three international benchmark thermal coal prices to reflect the fluctuations of global coal prices. As shown in Eq. 1, icp $\mathrm{jt}_{\mathrm{jt}}$ denotes the $\mathrm{j}$ benchmark coal price in period $t, c c p_{t}$ and refers to domestic coal price in China in period $t$ and $s t c p_{t}$ represents the standard deviation of the difference between the two.

$$
\operatorname{stcp}_{t}=\operatorname{stdev}\left(\mathrm{icp}_{\mathrm{jt}}-\mathrm{ccp}_{\mathrm{t}}\right)
$$

\section{(2) The proxy variable for medium- and long-term coal contracts}

Generally, the pricing policies of medium- and long-term coal contracts (the TCC) are recommended to encourage enterprises to sign coal contracts by administrative measures. Since the context of the TCC are textual materials, it is difficult to obtain quantitative variables directly based on real data. Thus, we employed the context analysis method (Bos and Tarnai, 1999; Huang et al., 2011) to mine the textual data for developing a proxy variable of the TCC. Meanwhile, it is found that all policy usually meets the general rule of diminishing effectiveness ${ }^{6}$, that is, a policy is effective when implemented, and then its effectiveness will gradually decline to zero (Imam, 2015). As shown in Figure 2, the related policies of the medium- and long-term contracts are issued with different time intervals. Based on the above analysis, we proposed that the law of diminishing effectiveness is correspond with the fact that the government issues repeatedly the same policy. Besides, Shimizutani (2006) empirically found that the

\footnotetext{
${ }^{6}$ Note that there are two theoretical reasons for the law of diminishing effectiveness. On one hand, since it takes time for the release and implementation of policies, the policy response is usually lagged behind economic changes. On the other hand, due to the existence of expectations of market players, the implementation of policies often deviates from their goals, which in turn will undermine the policies' effectiveness. Brainard (1967) proved that a structural change for the effectiveness of policy should be related to how it affects the policy-maker's performance in meeting his objectives.
} 
decrease in policy effectiveness may be rapid and is partly consistent with the exponential distribution. Given this, we assumed that the TCC meets the law of diminishing effectiveness of policies.

[Insert Figure 2]

Additionally, from the textual data of the TCC, a change in the definition of the coal contract period also attracted our attention. Specifically, the shortest period of the TCC declined from two years in P09 to one year in P13. Regardless of the sharp decline or sharp rise in coal prices, there will generally be an intention to default the contracts by at least one side of the contracts. In fact, the frequent default in coal contracts always has a negative impact on the stability of the coal market, forcing the government to adjust the coal contract period.

In view of the above situation, this paper chose the contract period of medium- and long-term contracts as the proxy variable, ranging from 12 to 24 months. Combining the law of diminishing effectiveness, we selected the natural exponential distribution function to simulate the proxy variable $c p c p_{t}$ (effective contract period) of the TCC, as shown in Eq.2. In the model, when $\mathrm{t}=1$, the pricing policy is released and the value of $c p c p_{t}$ is 24 . Then it begins to decline and stays stable until it drops to 12 in the same interval. Once a new pricing policy of the TCC is issued again, the above pattern of $c p c p_{t}$ is repeated. Hence, this paper simulates the time series of the proxy variable of the TCC $\left(c p c p_{t}\right)$ seen in Figure 3. 


$$
\operatorname{cpcp}_{\mathrm{t}}=12 * \mathrm{e}^{1-\mathrm{t}}+12,(t=1,2,3, \cdots n)
$$

In addition, we also proposed a proxy variable to capture the effect of joint-ministry policies. From 2013 to 2016, the coal pricing policies in Table 2 belonged to the same type of policies, i.e. notification policy, which means it is reasonable to choose the same proxy variable. Hence, we chose the proportion of the number of releasing ministries to the total number of ministries $\left(D P_{t}\right)$ following the practice of Sun and Cao (2012), to verify whether joint-ministry policies affect the relationship between policy factors and coal price fluctuations.

\section{[Insert Figure 3]}

\subsection{China's coal price transmission mechanism and expectation}

To stimulate the relationship among coal price, pricing policies, and coal supply and demand, it is necessary to discuss the transmission mechanism of coal price fluctuations. In general, China's current coal pricing policies tend to exhibit the behavior of control or ex post facto control. Thus, their forward-looking level is becoming a concern for the policy makers.

We proposed that the transmission mechanism of coal price fluctuations is a dynamic process that can be described as: changes in market indicators (including coal price, coal demand and supply) $\rightarrow$ pricing policy's formulation and release $\rightarrow$ expectations of market players $\rightarrow$ resource allocation of market players $\rightarrow$ new fluctuations of market indicators after the above policy implementation $\rightarrow$ new pricing policies, as 
seen in Figure 4. Although the pricing policies cannot be pre-intervened, the policy regulation is a continuous process while the major key state-owned coal enterprises that are owned and controlled by the central government in China have more market share, which to some extent, guarantees some regulatory effect. The transmission mechanism is specifically analyzed as follows:

[Insert Figure 4]

Firstly, as shown in Figure 4, when China's coal prices rise or fall sharply, it is difficult to stabilize coal price fluctuations solely through the market mechanism. Thus, the central government has tried to intervene by formulating a series of pricing policies. Note that differences in the releasing ministries and policy instruments may affect the relationship between pricing policies and coal price fluctuations. In 2008-2016, the makers of coal pricing policies changed from a single ministry to joint ministries, and the policy instruments gradually shifted from direct intervention to a portfolio with both direct and indirect interventions. Based on the above analysis, we put forward the following hypotheses: 1) choice of direct or indirect intervention affects the effects of pricing policies on coal price fluctuations; 2) different policy instruments have different impacts on the effectiveness of pricing policies; and 3) differences in the releasing ministries affect the relationship of pricing policy and coal price fluctuations.

Secondly, the release and implementation of coal pricing policies takes time to provide the conditions for market players' expectations on market fundamentals and the released 
policies, i.e. market expectation and policy expectation and the policy expectation is employed to represent the policy's forward-looking level (Sheffrin, 1996; Li, 2014). Under the assumption of bounded rationality, market players will make decisions about current and future production plans to maximize their benefits. Ultimately, their decisions will lead to fluctuations in coal prices. Note that the differences in policy instruments may affect policy expectation because on many occasions, the consequences of pricing policies maybe beyond policy makers' expectations (Shi et al, 2018). Given those information, we assumed that choice of policy instruments also affects policy expectation of market players and thus affects the forward-looking level of pricing policies.

\subsection{Empirical model and estimation strategy}

As shown in Figure 4, the theoretical relationship between coal price and pricing policies indicates that coal price $p_{t}$ depends on $p_{t-1}$ and the expected price fluctuation $\Delta p_{t}^{*}$ in the period t. Based on the expectation theory (Sheffrin, 1996), $\Delta p_{t}^{*}$ is affected by the current coal supply changes $\left(\Delta\right.$ supply $\left._{t}\right)$, the current coal demand changes $\left(\Delta\right.$ demand $\left._{t}\right)$, the lagged policy factors ${ }^{7}\left(\right.$ policy $\left._{t+n}\right)$ and other control variables ( control $\left._{t}\right)$. According to the transmission mechanism of coal price fluctuations in Section 3.2, the expectations including market expectation $\left(\Omega_{t-1}\right)$ and pricing policies expectation $\left(\Psi_{t+n}\right)$ are supposed to play a significant role in determining the changes in coal supply and demand in the period $t$.

\footnotetext{
${ }^{7}$ In this paper, we proposed that comparing to the direct impact of pricing policies, other policies seem have an indirect impact on coal price as their policy goals are not price regulation (Shi and Sun, 2017). Given this, we took the pricing policies set to represent the policy factor. 
Following the practices of Wang et al. (2013) and Sheng et al. (2014), we put forward a vector autoregressive model to analyze the impact of pricing policies on coal price fluctuations. The logarithmic function is as follows.

$$
\begin{gathered}
\operatorname{lnp}_{\mathrm{t}}=\rho * \ln _{\mathrm{t}-1}+(1-\rho) * \ln \Delta p_{t}^{*}+\varepsilon_{p} \\
\ln \Delta p_{t}^{*}=\alpha_{1} * E\left(\frac{\ln \Delta \text { supply }_{t}}{\Omega_{t-1} * \Psi_{t+n}}\right)+\alpha_{2} * E\left(\frac{\ln \Delta \text { demand }_{t}}{\Omega_{t-1} * \Psi_{t+n}}\right)+\alpha_{3} * \ln \text { polic }_{t+\mathrm{n}}+\alpha_{4} * \text { lncontrol }_{t}
\end{gathered}
$$

Then, the expected changes in coal supply and demand in this paper is replaced with actual values as follows.

$$
\begin{gathered}
\operatorname{lnp}_{\mathrm{t}}=\rho * \operatorname{lnp}_{\mathrm{t}-1}+(1-\rho) *\left[\alpha_{1} * \ln \Delta \text { supply }_{t}+\alpha_{2} * \ln \Delta \text { demand }_{t}+\alpha_{3}\right. \\
\left.* \ln \text { policy }_{t+\mathrm{n}}+\alpha_{4} * \text { lncontrol }_{t}\right]+\eta_{t} \\
\eta_{t}=(1-\rho) *\left[\alpha_{1} *\left(E\left(\frac{\ln \Delta \text { supply }_{t}}{\Omega_{t-1} * \Psi_{t+n}}\right)-\ln \Delta \text { supply }_{t}\right)+\alpha_{2} *\left(E\left(\frac{\ln \Delta \text { demand }_{t}}{\Omega_{t-1} * \Psi_{t+n}}\right)-\ln \Delta \text { demand }_{t}\right)\right]
\end{gathered}
$$

where, $t$ denotes the $\mathrm{t}^{\text {th }}$ month, $\rho, \alpha_{1}, \alpha_{2}, \alpha_{3}$ and $\alpha_{4}$ represent the elasticity coefficient of $\operatorname{lnp}_{t-1}, \ln \Delta$ supply $_{t}, \ln \Delta$ demand $_{t}, \ln _{\text {policy }}+n$ and lncontrol $_{t}$; $\eta_{t}$ refers to the residual value. Due to limitations in the monthly data, $\Delta$ supply $y_{t}$ denotes the difference of coal production in period $t$ and period $t-1$, while $\Delta$ demand $_{t}$ refers to the difference of coal sales in period $t$ and period $t-1$; policy $_{t}$ is a set of coal pricing policies and policy $_{t}=\left\{s t c p_{t}, c p c p_{t}, D P_{t}\right\}$ based on the construction of proxy variables in Section 3.1 and the optimal lag period of policy $_{t+n}$ is determined by the "goodness of fit" indicators in the regression model of coal price; control $_{t}=\left\{M A R K E T_{t}\right\}$ and $M_{\text {MRKET }}$ denotes marketization index which reflects the concentration level of China's coal market. ${ }^{8}$

$$
E\left(\frac{1}{\Omega_{t-1} * \Psi_{t+n}}\right)=\frac{\eta_{t}+(1-\rho) *\left(\ln \Delta \text { supply }_{t}+\ln \Delta \text { demand }_{t}\right)}{(1-\rho) *\left(\alpha_{1} * \ln \Delta \text { supply }_{t}+\alpha_{2} * \ln \Delta \text { demand }_{t}\right)}
$$

\footnotetext{
${ }^{8}$ Since China's coal market is not a fully competitive market, different companies have different bargaining powers for energy prices, which indicates that energy marketization affects energy price fluctuations (Ma and Oxley, 2012; Sheng et al., 2014).
} 
Based on Eq.4, this paper derives the expectation value $\left(\mathrm{E}\left(\Omega_{t-1} * \Psi_{t+n}\right)\right)$ of pricing policies as shown in Eq.5. In the equation, the market expectation $\left(E\left(\Omega_{t}\right)\right)$ refers to the chain of relative ratio of coal stock $\left(i v c q_{t}\right)$ to reflect the relationship between coal supply and demand; the policy expectation $\left(E\left(\Psi_{t}\right)\right)$ is assumed to be a uniform distribution variable of 0 to 1 and $E^{*}\left(\Psi_{t}\right)$ denotes the average value of $E\left(\Psi_{t}\right)$. According to Eq.4-Eq.5, the closer the value of $E^{*}\left(\Psi_{t}\right)$ is to 1 , the closer are the expected changes of coal supply and demand to the actual values, then the smaller the gap between the actual and expected coal price fluctuations, the better the forwardlooking nature of the policy.

To overcome potential endogeneity between coal price and coal supply or simultaneity issues due to omitted variables, this paper adopted a simultaneous equation system of coal price fluctuations and coal supply in the general method of moment (GMM) model, following the practice of Sheng et al. (2014). GMM is a parameter estimation method with the conditions that actual parameters should satisfy certain moment conditions, and a set of instrumental variables in the model should not relate to the disturbance term of the explanatory variables. Generally, GMM model is mainly employed in the studies with a big sample. However, Egger et al. (2009) proved that GMM Wald-test is correctly sized even in small samples, which verifies our monthly data in 2008-2016 is also feasible for GMM method in this paper.

The simultaneous equation system is shown as follows, in which a Douglas function is employed in the coal supply equation, and $L_{t}$ and $K_{t}$ represent the labor and capital stock of China's coal sector, respectively. In Eq.6, the final variables involved in the 
model include coal price, coal production, coal sales, the proxy policy variables of price restriction and medium- and long-term coal contracts, marketization index, labor and capital stock.

$$
\left\{\begin{array}{c}
\operatorname{lnp}_{\mathrm{t}}=\rho * \operatorname{lnp}_{\mathrm{t}-1}+(1-\rho) *\left[\alpha_{1} * \ln \Delta \text { supply }_{t}+\alpha_{2} * \ln \Delta \text { demand }_{t}\right. \\
\left.+\alpha_{3} * \ln \text { polic }_{t+\mathrm{n}}+\alpha_{4} * \text { lncontrol }_{t}\right]+\eta_{t} \\
\text { lnsupply }_{\mathrm{t}}=\beta_{1} * \ln \mathrm{p}_{\mathrm{t}}+\beta_{2} * \ln L_{t}+\beta_{3} * \ln K_{t}+\varepsilon_{y}
\end{array}\right.
$$

\subsection{Data}

The data used to conduct this research were drawn from a variety of sources as briefly explained blow. ${ }^{9}$ The spot prices of South Africa (Richards Bay), ARA port and Australia (Newcastle port), were obtained from the World Bank, while China's thermal coal price was collected from the China Coal Market Database (CCTD). The coal production and coal sales were retrieved from the China National Bureau of Statistics (NBS) database. The marketization index is defined by the ratio of output value of nonstate-owned enterprises and non-collective enterprises to the total output, which were retrieved from NBS database. On the coal supply side, the capital stock of China's coal sector is evaluated by the perpetual inventory method (Zhang et al., 2018) and the monthly data of the capital stock and coal sectoral employees in 2008-2016 were extracted from the CEIC database. As for the expectation factors, the coal inventory in China was obtained from the CCTD. The time trend regression method was used to simulate the missing value, which was not yet announced at the time of writing. All of the data were calculated using Eviews software and were adjusted by the Census X-12

\footnotetext{
${ }^{9}$ Note that after liberalization of coal prices in 2005, the Chinese government reformed its governance structure by establishing the National Energy Administration in 2008. To avoid the impact of the above institutional reform on coal price fluctuations, this paper selects monthly data of relevant variables from 2008 to 2016, resulting a total of 108 samples.
} 
seasonal method shown in Figure 5.

\section{Results and discussion}

In this section, we report the estimation results of price restriction policies and coal contracts policies respectively and then display the estimation of a portfolio that includes both policies. Lastly, we discuss the forward-looking policy efficient and robustness check.

Since most economic variables are usually in non-stationary sequences, we first checked the stationarity of the logarithmic coal price and other variables to avoid a heteroscedasticity issue (Cui and Wei, 2017). The Augmented Dickey Fuller (ADF) test shows that apart from the coal price $\left(C C P_{t}\right)$, the proxy variable of the TCC $\left(C P C P_{t}\right)$, marketization index $\left(M A R K E T_{t}\right)$, the labor $\left(L A B O R_{t}\right)$ and capital stock $\left(C A P I T A L_{t}\right)$ of China's coal sector are stationary series; three variables are first order difference stationary, including coal production $\left(C S_{t}\right)$, coal sales $\left(C D_{t}\right)$, and the policy proxy variable of the RCP $\left(S T C P_{t}\right){ }^{10}$ Therefore, we put the first-order difference of the three variables in Eq.6 and adopted the GMM method to examine the impact of pricing policies on coal price fluctuations in China.

[Insert Figure 5]

\subsection{Effect of the price restriction policies}

\footnotetext{
${ }^{10}$ Due to limited space, the results of the ADF test, following the Cointegration rank test are not provided. Please ask the author for the results if necessary.
} 
To avoid spurious regression, we performed the Granger Causality Tests and the Cointegration Rank Test, which indicated that there is a cointegrating equation at the 0.05 level. Then we carried out a simulation of coal price fluctuations with the lagging coal price and lagging independent variables as the instrument variables. The estimation results are shown in Table 3.

[Insert Table 3]

As shown in Function (a) of Model 1, since their coefficients are all positive at the 1\% level, it is clear that the lagging coal price and coal demand play an important role in determining coal prices. The optimal lag period of the price restriction policies is set at one month according to the values of R-squared and Durbin-Watson, which implies the price restriction policies play a quick role in regulating coal prices. Meanwhile, in Function (b), the regression results of coal supply show that both labor and capital stocks provide positive guidance for coal supply while the current increase in coal prices will stimulate a rise in coal production, and then the added production will cause the future coal price to decline since the coefficient of $D(C S)$ is negative at the $1 \%$ level, satisfying the general rules of microeconomics.

The key value of interest, namely the policy effectiveness, is demonstrated. However, the actual effectiveness of the price restriction policies was not as good as expected because the absolute value of the coefficient of $D(S T C P(1))$ (about -0.022$)$ is the smallest. A possible explanation is that the price restriction policies are short-term 
policy tools by setting the coal price ceiling directly and in the long term, the effectiveness of the RCP depends on the government's monitoring capability and the rebound effect of market-oriented coal prices. This finding indicates that when choosing direct price intervention, the government should not only consider the short-term response ability of the policy instrument, but also its long-term effectiveness.

In Function (a), the marketization index has a significantly negative impact on the coal price at the $1 \%$ level, which means the rising output value of non-stated enterprises in China's industrial sectors can contribute to the decline in coal price due to increased market competition, which is consistent with Sheng et al (2014).

\subsection{Effect of medium- and long-term coal contracts}

Similarly, the results of the Cointegration Rank Test showed there is a cointegrating equation of coal price and coal demand, coal supply, the proxy variable of the TCC $(C P C P)$ and the marketization index at the 0.05 level. The estimation results in Function

(a) are shown in Model 2, presented in the third and fourth columns of Table 4. Note that compared with the single-ministry policy, the joint-ministry policy may have an exogenous effect on the coal price. Thus, we introduced the proportion of joint ministries $(D P)$ in Model 3, shown in the fifth and sixth columns of Table 4.

[Insert Table 4]

The coefficients of $D(C D)$ and $D(C S)$ manifest that compared with coal supply, coal 
demand have a greater impact on coal price fluctuations, as presented in Model 3. Moreover, the optimal lag period of the TCC is set at 8 , suggesting that it takes an average of 8 months for the TCC to regulate the coal price after being published in China, which is in stark contrast to the lagging effect of the price restriction policies. An interesting finding is that the coefficient of $C P C P$ is positive and quite low $(0.019)$ at the 0.01 level, which means that this contractual intervention may not significantly curb the coal price fluctuations. There could be three reasons. First, the implementation of the TCC has a low efficiency due to the poor policy expectation. Generally speaking, indirect intervention does not respond quickly to fluctuations in coal prices with a loss of policy information in the implementation process, which generates a deviation from the policy expectation of market players and ultimately reduces the effectiveness of the TCC.

Second, the way in which the pricing policies are released may affect their effectiveness. Specifically, where ministries jointly publish policies in the formulation stage is a key factor. Unlike the finding of Oikonomou et al. (2012), we found that the effect of the TCC will be influenced by the joint efforts among ministries. In Model 3, when considering the influence of the release method $(D P)$, the coefficient of $C P C P(-0.03)$ is negative and is obviously contrary to that in Model 2 at the $10 \%$ level, which proves that the joint release method has a significant impact on the relationship between coal price fluctuations and the TCC. This finding indicates that when improving the coal pricing mechanism of medium- and long-term coal contracts, the government ought to seek cooperation across ministries to reduce the policy distortion in the price 
marketization process.

However, the estimated coefficient of the $D P$ is positive 0.19 and contrary to expectations due to the limitation of the sample period in this paper. As shown in Table $1-2$, the fact is that without considering other types of policies, single-ministry pricing policies were used by the Chinese government to regulate coal price fluctuations during most of the sample period and this covers up the real negative effect of the joint release method on coal price fluctuations.

The third explanation is that the contracts are not strictly enforced and will therefore not have a real impact. As mentioned in Section 3.1, at least one party in the contracts has incentive to default. As the government does not have information on the actual enforcement, the policy is not likely to be effective.

\subsection{Effect of coal pricing policy portfolio}

Based on the analysis in Section 2.2, the policy portfolio of coal prices, was performed during the period of 2013-2016, providing an opportunity to analyze the synergies effect of a policy portfolio. The estimation results demonstrate that in Model 4 shown in Table 4.

In fact, the central government has tried hard to reduce its interventions from 2013, especially to reduce the local government's protectionism, for enhancing the market's self-determination of coal prices. However, from Models 1-4, the coefficients of coal supply and demand had a dramatic downward trend from 2008 to 2016, as well as the actual elasticity of the marketization index. This finding implies that the impact of policy factors on coal price fluctuations will become increasingly important. 
Meanwhile, the coefficient of $\operatorname{STCP}(3)$ in Model 4 is significant and slightly larger than the coefficient of $C P C P(8)$ at the 0.1 level, directly proving that different policy instruments have different influences on coal prices. Besides, what surprises us is the

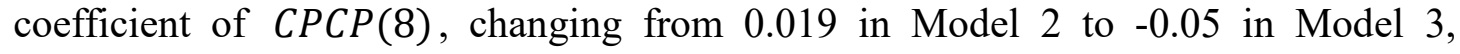
indicating that the impact of the TCC had been strengthened dramatically when considering the pricing restriction policy. In the same way, a synergy effect was identified in China's coal pricing policies from 2013 to 2016, suggesting that in regulating coal prices, the effect of a policy portfolio is much stronger than any single direct or indirect policies. Thus, it is recommended that the government adopt multiple policy tools to improve the effectiveness of pricing regulations.

Another interesting finding is that the optimal lag period of the price restriction policies in Model 4 is three months while it is one month in Table 3, implying that the response speed of the price restriction policies in 2013-2016 is obviously weaker than the coal price ceiling. But in long-term regulation, the effect of the former $(-0.06)$ is undoubtedly better than the latter $(-0.02)$. Hence, the balance between response speed and the effectiveness of pricing polices is of great concern to the Chinese government as well as to other governments in their attempts to implement energy price marketization.

\subsection{The forward-looking policy coefficient}

While in the medium to long run, coal prices should be determined by the market, the current pricing policies could be improved through designing a forward-looking pricing policy. According to the estimated results in Eq. 6, we can derive the values of the 
forward-looking coefficient $\left(E^{*}\left(\Psi_{t}\right)\right)$ by Eq.5 under three different scenarios respectively, as shown in Fig. 6.

In Figure 6, all the coefficients are below 0.5, indicating that the overall forwardlooking level of China's coal pricing policies is unsatisfactory as expected due to the typical post-event response strategies in 2008-2016. With lagging pricing policies, distortions in coal prices can be generated to affect the efficiency of resource allocation (Ju et al., 2017; Shi and Sun, 2017). While China's coal industry is looking for new interests to meet the needs of the energy transition, the increasingly frequent fluctuations in coal prices is also severely challenging the forward-looking level of pricing policies.

Meanwhile, the difference in the values of E1 and E2 indicates that the forward-looking level of indirect intervention is much better than that of direct intervention, proving that the choice of the policy instruments directly affects not only the effectiveness but also the forward-looking level. Further, the value of E3, a significant increase over the value of E2, shows that the release method also has an obvious impact on the forward-looking level of pricing policies and thus meets the theoretical expectations in this paper.

Additionally, this paper found that the government needs to balance the effectiveness and foresight of coal pricing policies. In details, although the value of E4 is obviously smaller than that of E2, the synergy effect of the policy portfolio in Model 4 was clearly better than that of single price policy in Model 2. This finding seems to produce a pseudo-proposition for the government to pursue forward-looking and effective pricing policies. Indeed, the effectiveness of any policy can be affected by its formulation, 
publication, and implementation. During the formulation of coal pricing policies, we suggest that policy makers focus on the policy's forward-looking level, and then to improve its effectiveness in the implementation process by optimizing the linkage mechanism of multiple departments.

[Insert Figure 6]

\subsection{Robustness check}

To test the robustness of the regression results, we used the coal price index (based on January 2011) as the dependent variable instead of thermal coal price. The simulated results of the conductive direction of independent variables obtained by the same regression techniques are similar to those we derived from the regression model for thermal coal price, and there is a little variation in the coefficients of all the variables. Thus, our findings are robust to alternative measures of coal price.

\section{Conclusions and policy implications}

Price fluctuations are regarded as the key driver of the interventions. Although the Chinese government has been liberalizing its market in recent years, the coal industry has been subject to frequent price interventions. The apparent contradiction provides a case for interesting academic investigation that has important implications for China's coal industry, and also for the coal industries of other countries.

In this paper, we introduced market players' expectations in the transmission mechanism of coal price fluctuations in China to derive the relationship between coal 
price fluctuations and pricing policies. We also separated coal pricing policies spanning the 2008 to 2016 period into two stages and proposed a novel measurement of different pricing policies. Then we built simultaneous equations for coal price and coal supply and innovatively constructed a forward-looking coefficient to evaluate different coal pricing policies in 2008-2016. Lastly, we measured and analyzed the impacts of different pricing policies on coal price fluctuations employing the GMM method and discussed the forward-looking level of coal pricing policies, leading to new path explorations for price intervention in coal and other energy sectors.

The estimation results proved that different pricing policies in China have had different impacts on coal price fluctuations due to differences in market players' expectations, policy instruments and the release method. Moreover, this paper empirically concluded that the policy portfolio from 2013 to 2016, to some extent, amplified the impact of pricing policies on coal price fluctuations. The above results answer the first two questions raised in this paper and several key findings included: firstly, both the lagging coal price and coal demand have a significant positive impact on coal price fluctuations, while coal supply and market integration play a negative role in regulating coal prices. Secondly, when considering the joint release method, the pricing policies of mediumand long-term coal contracts have an inhibitory effect on prices with an average lag period of 8 months. When considering the combination between direct and indirect interventions, the synergy effect of a policy portfolio is generated to regulate coal prices, and the effectiveness of both price restriction and coal contracts policies has also been strengthened. Thirdly, the long-term effects of different price restriction policies in 
regulating coal prices are different while the coal price ceiling is identified as a fastresponding policy tool with the lag period of one month. Fourthly, while policy factors play an increasingly important role in China from 2008 to 2016, the impact of market factors on coal price fluctuations is weakening, which suggests that despite aiming for overall liberalization of prices, coal prices in China have been increasingly distorted by policy interventions. Lastly, the forward-looking level of China's coal pricing policies, relatively low as expected, is proved to be affected by the choice of policy instruments. Our study suggests that while pricing policies may be necessary for controlling coal price fluctuations amidst China's energy transition, it is not realistic to rely on the current pricing mechanism and the Chinese government need to advance marketization of coal prices amid the energy transition. Further, the government should improve the design of the forward-looking pricing policy with the balance between quick response and long-term effectiveness. That is, the government can prepare a long-term effective policy instrument during the process of coal pricing to keep coal market in good order to a quickly responsive tool in monitoring coal prices to prevent market failures.

In the short term, for improving the forward-looking level of China's coal pricing policies, the policy instruments should be designed to reflect market fundamentals instead of stabilizing energy prices, just as a market-oriented price does. Moreover, with its inhibitory effect on prices, the policy of medium- and long-term contracts could be useful in building stable market expectation. One possible way to improve the contractual arrangement is to adopt market-determined "benchmark prices" as the transaction prices. Besides, due to the synergy effect of a policy portfolio, coordination 
among ministries and combination of various policy instruments are also necessary to improve the effectiveness of current pricing policies. Lastly, except for the significant impacts of pricing policies on coal price fluctuations, other policies such as industrial adjustment policies and environmental regulation policies, seems to have indirect influence on coal prices (Shi and Sun, 2017). It suggests that the government needs to coordinate the pricing policies with the policies for protecting economic growth and environment development.

Although we suggest to improve the effectiveness of policy intervention on pricing, we do not deny that in the medium- to long term, the government could abolish coal price interventions in line with the current overall national economic reform agenda (18th Central Committee of the Communist Party of China, 2013). This long-term strategy in regulating coal prices is consistent with several scholars' work (Wang et al., 2009; Cui and Wei, 2017; Shi and Sun, 2017). In order to mitigating unreasonable price fluctuations under a liberalized price environment, the pricing mechanism should be well developed to reflect market fundamentals. The government is suggested to make continuous efforts to improve market transparency by installing and implementing markets rules, aiming to let coal prices to be determined by market fundamentals. Lastly, further development of a derivative market in China's coal industry is needed to add liquidity to the market, to generate efficient market prices and to provide an instrument of market players to manage price risks.

Two caveats need to be highlighted and could be directions for future studies. On one hand,we only considers a limited number of impact factors. Other policies whose may have 
indirect impact on coal price, such as coal capacity cut policy, could be further added to our model. On the other hand, the policies were not quantitated and the data series is limited. Further studies could be made to quantitate policies with extend date series overtime.

\section{Acknowledgements}

This study is supported by the National Natural Science Foundation of China (No. 71828401,No. 71273259, No. 71403267 and No. 71473250); the Fundamental Research Funds for the Central Universities (No. 2017BSCXB21); Postgraduate Research \& Practice Innovation Program of Jiangsu Province (No. KYCX17_1503); the Key Project of Philosophy and Social Science Research in Universities of Jiangsu Province (No. 2017ZDIXM162); the Postdoctoral Science Foundation of China (No. 2014M551683) and the Graduate Education Reform Project of China University of Mining and Technology (No.YJSJG_2017_048). 


\section{References}

18th Central Committee of the Communist Party of China, 2013. Decision of the Central Committee of the Communist Party of China on Some Major Issues Concerning Comprehensively Deepening the Reform, china.org.cn.

Adelman, M.A., 1974. Politics, Economics, and World Oil. Am. Econ. Rev. 64.

Andrews-Speed, P., Ma, G., Shao, B., Liao, C., 2005. Economic responses to the closure of small-scale coal mines in Chongqing, China. Resour. Policy 30, 39-54. https://doi.org/10.1016/j.resourpol.2004.12.002

Batini, N., Haldane, A.G., 1999. Forward-Looking Rules for Monetary Policy, Monetary Policy Rules. https://doi.org/10.2139/ssrn.147549

Bernanke, B.S., Gertler, M., Watson, M., 1997. Systematic Monetary Policy and the Effects of Oil Price Shocks. Brookings Pap. Econ. Act. 1997, 91-157. https://doi.org/10.2307/2534702

Best, G., Kapinos, P., 2016. Monetary policy and news shocks: Are Taylor rules forward-looking? B.E. J. Macroecon. 16, 335-360. https://doi.org/10.1515/bejm-2014-0161

Bloxham, P., 2018. Resources are still boosting Australia despite China slowdown [WWW Document]. https://doi.org/http://www.afr.com/opinion/columnists/resources-are-still-boosting-australiadespite-china-slowdown-20180417-h0yv6c

Bos, W., Tarnai, C., 1999. Content analysis in empirical social research. Int. J. Educ. Res. 31, 659-671. https://doi.org/10.1016/S0883-0355(99)00032-4

BP, 2018. Statistical Review of World Energy 2018. British Petroleum, London.

Brainard, W.C., 1967. Uncertainty and the Effectiveness of Policy. Am. Econ. Rev. 57, 411-425.

Cui, H., Wei, P., 2017. Analysis of thermal coal pricing and the coal price distortion in China from the perspective of market forces. Energy Policy 106, 148-154.

https://doi.org/10.1016/j.enpol.2017.03.049

Ding, Z., Feng, C., Liu, Z., Wang, G., He, L., Liu, M., 2017. Coal price fluctuation mechanism in China based on system dynamics model. Nat. Hazards 85, 1151-1167. https://doi.org/10.1007/s11069-016-2626-0

Edelstein, P., Kilian, L., 2009. How sensitive are consumer expenditures to retail energy prices? J. Monet. Econ. 56, 766-779. https://doi.org/10.1016/j.jmoneco.2009.06.001

Egger, P., Larch, M., Pfaffermayr, M., Walde, J., 2009. Small sample properties of maximum likelihood versus generalized method of moments based tests for spatially autocorrelated errors. Reg. Sci. Urban Econ. 39, 670-678. https://doi.org/10.1016/j.regsciurbeco.2008.09.003

Ellerman, A.D., 1995. The world price of coal. Energy Policy 23, 499-506. https://doi.org/10.1016/0301-4215(95)91231-Z 
Haris, M.P., Tao, J., 2016. Role of governance in creating a commodity hub: A comparative analysis. Nat. Gas Ind. B 3, 367-376. https://doi.org/http://dx.doi.org/10.1016/j.ngib.2016.12.001

Huang, C., Su, J., Shi, L., Cheng, X., 2011. Textual and quantitative research on Chinese wind energy policy system from the perspective of policy tools (in Chinese). Stud. Sci. Sci. 876-882. https://doi.org/10.16192/j.cnki.1003-2053.2011.06.012

Imam, P.A., 2015. Shock from graying: Is the demographic shift weakening monetary policy effectiveness. Int. J. Financ. Econ. 20, 138-154. https://doi.org/10.1002/ijfe.1505

ITC, 2017. Trade Map, http://www.trademap.org/ (Accessed 26 May 2017).

Ji, S., Zhang, Y., Tooraj, J., 2014. Reform of the Coal Sector in an Open Economy: The Case of China. Univ. Cambridge, Energy Policy Res. Gr. Work. Pap.

Ju, K., Su, B., Zhou, D., Wu, J., 2017. Does energy-price regulation benefit China's economy and environment? Evidence from energy-price distortions. Energy Policy 105, 108-119. https://doi.org/10.1016/j.enpol.2017.02.031

Kanamura, T., 2009. A supply and demand based volatility model for energy prices. Energy Econ. 31, 736-747. https://doi.org/10.1016/j.eneco.2009.04.001

Kilian, L., 2009. The Economic Effects of Energy Price Shocks. J. Econ. Lit. 46, 871-909. https://doi.org/10.1257/jel.46.4.871

Leduc, S., Sill, K., 2004. A quantitative analysis of oil-price shocks, systematic monetary policy, and economic downturns. J. Monet. Econ. 51, 781-808. https://doi.org/10.1016/j.jmoneco.2003.09.004

Li Laya, 2014. A Revised Sargent-Wallace Model and the Management of Expectations. Int. J. Innov. Manag. Inf. Prod. 5, 44-48.

Littlechild, S., 2014. RPI-X, competition as a rivalrous discovery process, and customer engagement Paper presented at the Conference The British Utility Regulation Model: Beyond Competition and Incentive Regulation? Util. Policy 31, 152-161. https://doi.org/10.1016/j.jup.2014.09.008

Liu, M., Chen, M., He, G., 2017. The origin and prospect of billion-ton coal production capacity in China. Resour. Conserv. Recycl. 125, 70-85. https://doi.org/10.1016/j.resconrec.2017.05.015

Lüthi, S., Wüstenhagen, R., 2012. The price of policy risk - Empirical insights from choice experiments with European photovoltaic project developers. Energy Econ. 34, 1001-1011. https://doi.org/10.1016/j.eneco.2011.08.007

Ma, H., Oxley, L., 2012. The emergence and evolution of regional convergence clusters in China's energy markets. Energy Econ. 34, 82-94. https://doi.org/10.1016/j.eneco.2011.02.015

Ma, H., Oxley, L., 2010. The integration of major fuel source markets in China: Evidence from panel cointegration tests. Energy Econ. 32, 1139-1146. https://doi.org/10.1016/j.eneco.2010.02.001

Ma, H., Oxley, L., Gibson, J., 2009. Gradual reforms and the emergence of energy market in China: Evidence from tests for convergence of energy prices. Energy Policy 37, 4834-4850. https://doi.org/10.1016/j.enpol.2009.06.055 
Oikonomou, V., Flamos, A., Zeugolis, D., Grafakos, S., 2012. A qualitative assessment of EU energy policy interactions. Energy Sources, Part B Econ. Plan. Policy 7, 177-187. https://doi.org/10.1080/15567240902788996

Papiez, M., Śmiech, S., 2013. Causality-in-mean and causality-in-variance within the international steam coal market. Energy Econ. 36, 594-604. https://doi.org/10.1016/j.eneco.2012.11.004

Sheffrin, S.M., 1996. Rational Expectations, Cambridge Surveys of Economic Literature. https://doi.org/DOI: 10.1017/CBO9781139174367

Sheng, Y., Shi, X., Zhang, D., 2014. Economic growth, regional disparities and energy demand in China. Energy Policy 71, 31-39. https://doi.org/10.1016/j.enpol.2014.04.001

Shi, X., 2013. China's small coal mine policy in the 2000s: A case study of trusteeship and consolidation. Resour. Policy 38, 598-604. https://doi.org/10.1016/j.resourpol.2013.09.009

Shi, X., 2009. Have government regulations improved workplace safety?. A test of the asynchronous regulatory effects in China's coal industry, 1995-2006. J. Safety Res. 40, 207-213. https://doi.org/10.1016/j.jsr.2009.03.005

Shi, X., Rioux, B., Galkin, P., 2018. Unintended consequences of China's coal capacity cut policy. Energy Policy 113, 478-486. https://doi.org/10.1016/j.enpol.2017.11.034

Shi, X., Sun, S., 2017. Energy price, regulatory price distortion and economic growth: A case study of China. Energy Econ. 63, 261-271. https://doi.org/10.1016/j.eneco.2017.02.006

Shimizutani, S., 2006. Consumer response to the 1998 tax cut: Is a temporary tax cut effective? J. Jpn. Int. Econ. 20, 269-287. https://doi.org/10.1016/j.jjie.2005.04.001

Simshauser, P., 2017. Monopoly regulation, discontinuity \&amp; stranded assets. Energy Econ. 66, 384-398. https://doi.org/10.1016/j.eneco.2017.06.029

State Council, 2016. 国务院关于煤炭行业化解过剩产能实现脱困发展的意见(Opinions of the State Council on Reducing Overcapacity in the Coal Industry to Achieve Development by Solving the Difficulties), Guofa [2016] 7. State Council of PRC, Beijing.

State Council, 2012. 关于深化电煤市场化改革的指导意见(Notice on deepening the market-oriented reform of thermal coal price), Guobanfa [2012] 57. General Office, State Council PRC, Beijing.

Sun, Q., Xu, L., Yin, H., 2016. Energy pricing reform and energy efficiency in China: Evidence from the automobile market. Resour. Energy Econ. 44, 39-51. https://doi.org/10.1016/j.reseneeco.2016.02.001

Sun, Y., Cao, C., 2012. An Empirical Study on the Cooperative Structure Evolution of China's Innovation Policymakers Under the Background of Strategic Scene Change (in Chinese). R \& D Manag. 24, 93-102.

Wang, D., Zhang, Y., Yin, Q., Nie, R., 2013. Coal Price Volatility and Price Discovery Function in China (in Chinese). Resour. Sci. 35, 1643-1650.

Wang, M., Tian, L., 2015. Regulating effect of the energy market-Theoretical and empirical analysis based on a novel energy prices-energy supply-economic growth dynamic system. Appl. Energy 
155, 526-546. https://doi.org/10.1016/j.apenergy.2015.06.001

Wang, Q., Qiu, H.N., Kuang, Y., 2009. Market-driven energy pricing necessary to ensure China's power supply. Energy Policy 37, 2498-2504. https://doi.org/10.1016/j.enpol.2009.03.008

Weyman-Jones, T.G., 1990. RPI-X price cap regulation. The price controls used in UK electricity. Util. Policy 1, 65-77. https://doi.org/10.1016/0957-1787(90)90010-I

Yoon, J.H., Sim, K. ho, 2015. Why is South Korea's renewable energy policy failing? A qualitative evaluation. Energy Policy 86, 369-379. https://doi.org/10.1016/j.enpol.2015.07.020

Zhang, C., Dang, C., 2018. Is monetary policy forward-looking in China? Int. Rev. Econ. Financ. https://doi.org/10.1016/j.iref.2018.02.009

Zhang, H., Cheng, J., 2011. Dynamic effect of China's energy price fluctuations and resident consumption levels: verification based on the VAR model and SVAR model (in Chinese). Resour. Sci. 33, 806-813.

Zhang, Y., Nie, R., Shi, R., Zhang, M., 2018. Measuring the capacity utilization of the coal sector and its decoupling with economic growth in China's supply-side reform. Resour. Conserv. Recycl. 129, 314-325. https://doi.org/10.1016/j.resconrec.2016.09.022

Zhang, Y., Zhang, M., Liu, Y., Nie, R., 2017. Enterprise investment, local government intervention and coal overcapacity: The case of China. Energy Policy 101, 162-169. https://doi.org/10.1016/j.enpol.2016.11.036

Zhao, X., Ma, C., Hong, D., 2010. Why did China's energy intensity increase during 1998-2006: Decomposition and policy analysis. Energy Policy 38, 1379-1388. https://doi.org/10.1016/j.enpol.2009.11.019

Zheng, T., Wang, X., Guo, H., 2012. Estimating forward-looking rules for China's Monetary Policy: A regime-switching perspective. China Econ. Rev. 23, 47-59. https://doi.org/10.1016/j.chieco.2011.07.012 